\title{
CRIANÇAS E JOVENS NA PRAIA: VERSÕES E SUBVERSÕES
}

\begin{abstract}
Renan $\boldsymbol{J i}$ é doutorando em Literatura Comparada na Universidade Federal Fluminense e pesquisa os seguintes temas: infância, sexualidade, poéticas clássicas em perspectiva comparada, literatura e cultura brasileiras. E-mail: renanji@hotmail.com

Resumo

Análise de dois momentos de representação da infância e da juventude, apontando semelhanças e diferenças que possibilitam uma reflexão acerca das imagens culturais consagradas do corpo juvenil.

Abstract

Analysis of two figurations of childhood and youth specifying differences and similarities, which will make possible a reflection on the traditional cultural images of the young body.
\end{abstract}

Comecemos com o seguinte trecho de Thomas Mann e com a imagem que faz parte do desfecho do filme Morte em Veneza, de Luchino Visconti (1971):

\begin{abstract}
À beira do mar ficou parado de cabeça baixa, desenhando figuras na areia úmida com as pontas dos pés, e depois entrou na parte rasa, que no seu ponto mais fundo ainda não molhava os joelhos, adiantou-se descuidadamente e alcançou o banco de areia. Ali ficou em pé durante um momento, o rosto voltado para a distância; depois começou a andar vagarosamente para a esquerda, pela extensão comprida e estreita do fundo descoberto. Separado da terra firme por faixa de água e dos companheiros por um capricho orgulhoso, vagueava, uma imagem altamente distante e desligada, com o cabelo esvoaçando, lá fora no mar, no vento, defronte ao nebuloso ilimitado. Novamente, parou para a espreita. E repentinamente, como sob uma lembrança, sob um impulso, virou o tronco, uma das mãos nos quadris, numa rotação bonita de sua pose fundamental, e olhou sobre os ombros para a praia. O observador ali estava sentado, como em outra oportunidade estivera, quando, pela primeira vez, este olhar cinza-alvorada correspondera encontrando o seu. Sua cabeça, encostada no espaldar da cadeira, seguira vagarosamente os movimentos daquele que andava lá fora; agora ergueu-se como que de encontro ao olhar, e caiu sobre o peito, de modo que seus olhos viam por baixo, enquanto seu rosto apresentava a indolente, afetuosa e meditativa expressão do sono profundo. Mas pareceu-lhe que o pálido e gracioso psicagogo lá fora lhe sorria, lhe acenava, como se, soltando a mão dos quadris, apontasse para fora, flutuando na sua frente para a imensidão auspiciosa. E, como tantas vezes, levantou-se para segui-lo.

Minutos se passaram até virem em auxílio do que caíra de lado na cadeira. Levaram-no para o seu quarto. E, ainda no mesmo dia, um mundo respeitosamente comovido recebeu a notícia de sua morte (MANN, 1979, p. 170).
\end{abstract}




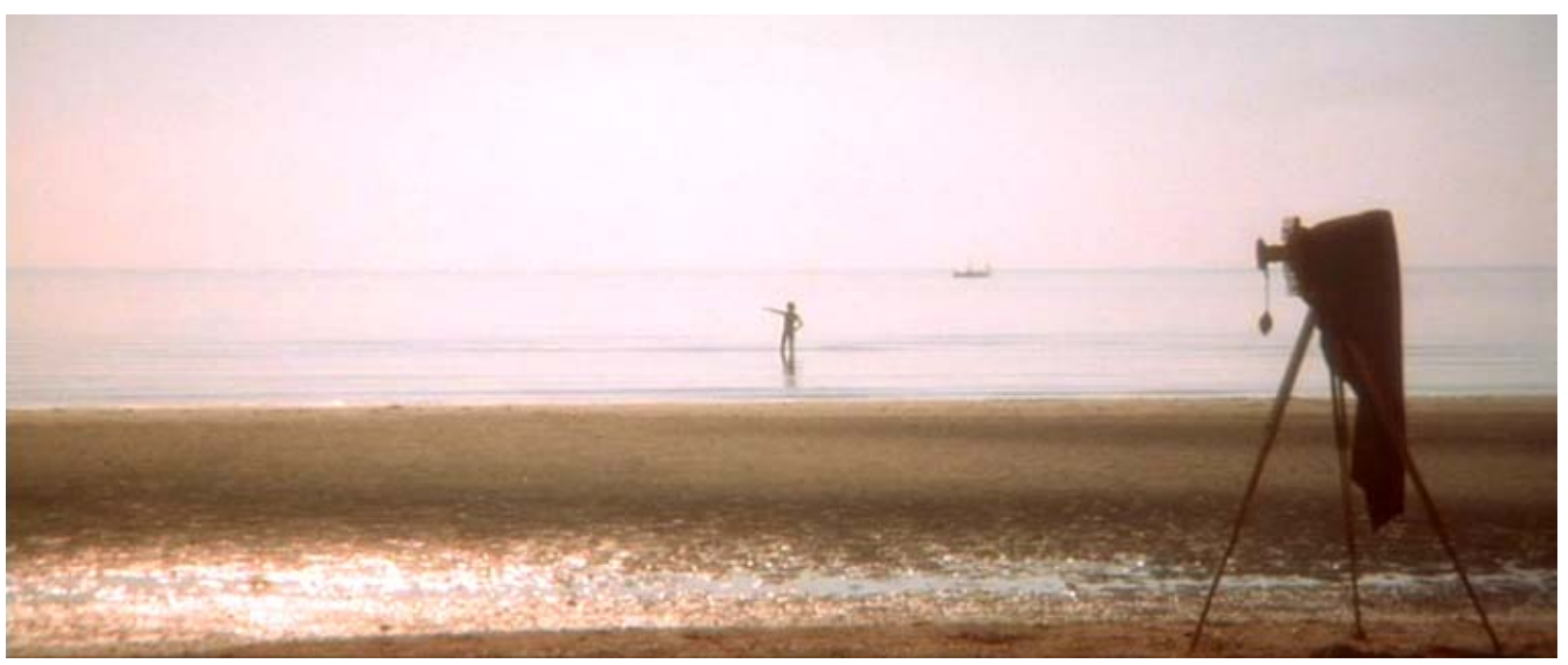

Cena final de Morte em Veneza, de Luchino Visconti ${ }^{1}$

As cenas em questão, tanto a literária quanto a cinematográfica, representam o ápice de um jogo de perseguição estabelecido entre um famoso artista e um enigmático rapaz. O jovem Tadzio parece manter com o seu perseguidor uma relação de sedução e fuga: retribui os olhares vexados de Gustav von Aschenbach, porém permanece inatingível numa espécie de alheamento, na sua rotina pré-adolescente de brincadeiras e passeios, numa Veneza marcada por signos da decadência. A Veneza de Thomas Mann se afoga nas próprias águas e na doença, espelhando o naufrágio físico e social do próprio Aschenbach - em oposição à beleza fulgurante do jovem, que permanece indiferente e apolíneo ao caos social (e estético) provocado pela peste que assola a ilha. Tadzio suplanta totalmente o cenário de destruição ao surgir gloriosamente no fim da narrativa, estátua grega que aponta para o horizonte. Anuncia não só a morte do contemplador ofuscado, mas aponta para a total redenção da experiência estética, na direção do inefável ou do sublime das formas, da "imensidão auspiciosa" figurada pelo mar. Aqui, percebe-se que a juventude descortina o reino da beleza universal; a inocência do rapaz é o último resquício de uma vida divina, da qual nos encontramos definitivamente apartados.

Nessa perspectiva, tomemos o jovem Tadzio como protótipo de uma relação que a cultura e a arte estabelecem com a infância e a juventude. Glorificamos e protegemos a criança ou o jovem precisamente por serem um contraexemplo da vida adulta, alheio à convenção social, ao mundo do trabalho e à sexualidade. De forma sintomática, atribuímos à jovialidade uma centelha do divino e, por isso, louvamos a sua total liberdade e hedonismo, valores que encontram redenção no terreno beatífico da inocência. Mas não seria somente por esse fato que esse estágio inicial da existência humana se torna objeto de devoção e cuidado. Afinal, ele se caracteriza por um tênue equilíbrio, por uma beleza em suspensão fadada a desaparecer. Ronda-nos o fato de que a inevitável marca da experiência sulcará o corpo intocado. Assim, na beleza clássica do efebo, temos a lembrança inevitável 
do que já foi perdido - daí, portanto, o olhar fascinado e a tentativa de resguardar a todo custo uma preciosa efemeridade, prolongando essa existência divina e inconsciente. Daí a visão altamente estetizada e utópica, o gozo artisticamente sublimado e asséptico, livre de todo contato físico e íntimo.

Assim é que Gustav von Aschenbach - e, por extensão, o próprio leitor / espectador dessa história que se passa em Veneza - estabelece com a figura do "pálido e gracioso psicagogo" uma dinâmica similar à que estabelecemos com a inocência da primeiras fases da vida: uma relação de fascinação e contemplação, de aproximação e fuga. O Tadzio de Thomas Mann se apresenta como pura visualidade, permanecendo num campo de contemplação estética que, paradoxalmente, retira do infante seu aspecto mundano, tangível, corporal. A imagem final de Luchino Visconti resume bem essa dupla articulação: a graça juvenil é apreciada como horizonte longínquo, livre da aproximação, do toque, da sexualidade, e indiferente à avidez de um olhar perscrutador e desejante, que por sua vez é instigado pelo próprio distanciamento. A criança e o jovem, nesse sentido, pertencem por excelência ao campo da idealização, sendo um ideal que não raro seduz, mas mantém isolamento de qualquer contato que corrompa sua suposta inocência e pureza.

É curioso observar que, se levarmos em conta a tradição romântica da qual legamos o imaginário acerca da infância - consagrada, de acordo com Reinhard Kuhn (1982), a partir do Emílio de Rousseau (1995) — , a narrativa fortemente sublimada e artística de Mann talvez pudesse despertar certa reserva moral. Afinal, de acordo com Phillipe Ariés (1962), são séculos de gestação de um ideal que, nascido da constatação da natureza singular da criança perante o adulto (ainda durante a era medieval), chega ao século XVIII imbricado a um projeto de família burguesa que englobava a antiga moral religiosa e absorvia novos valores, como os cuidados higiênicos com o corpo, criando-se uma aura de inocência e pureza que deveria ser protegida a todo custo.

Diante desse ideal específico, que impôs todo um imaginário e uma iconografia acerca da infância, a figura de Tadzio talvez pareça algo incômoda, pois haveria uma sutil dubiedade no comportamento do rapaz: ele inequivocamente responde aos olhares de seu admirador, como se soubesse ser objeto de desejo e contemplação. Nesse caso, assevero que o julgamento do que objetivamente estaria por trás desse olhar ambíguo interessaria, talvez, aos censores. Porém, levando a questão para o campo da reflexão, devemos admitir que esse olhar traz à tona uma quebra de sentido - uma fratura no edifício ideológico e imaginário criado ao redor da infância. O infante que devolve o olhar de um observador anuncia a presença de uma subjetividade, pensante e singular, possuidora de motivações e afetos, dotada de um corpo que lhe fornece todo tipo de sensações, aspectos muitas vezes ignorados pelas visões tradicionais da infância e até mesmo da adolescência.

Seja na literatura, no cinema ou na fotografia, falamos aqui de imagens. Nessas imagens, testemunhamos "um olhar profundamente ambíguo - um olhar que nos intima a uma perspectiva alternativa, esquivando-se da autoridade do fotógrafo e do espectador" 
(LUMBY, 2010, p. 8). Imagens desse tipo prenunciam a viragem de uma visão que construiu a categoria da infância e da juventude como idílio da inocência, da pureza, da inconsciência e da neutralidade. A propósito dessa viragem, Anne Higonet (1998), em Pictures of innocence, fala de uma crise no ideal de infância que se dá no próprio seio da concepção romântica de inocência infantil. Examinando fotos e imagens que celebraram e construíram ideologicamente a figura da criança no século XVIII, Higonet mostra que no próprio campo da idealização surgem pontos cegos ou dissimetrias, através dos quais flagramos a ambiguidade de um olhar devolvido ao espectador, um relance de nudez, a sugestão erótica de um simbolismo. Elementos que participam da iconografia da infantilidade e da inocência do século XVIII e que, ao mesmo tempo, sinalizam a sua ruína. Em Thomas Mann, essa ambiguidade se apresenta da forma mais aguda: Tadzio, detentor do sublime estético proporcionado pela arte, aponta simultaneamente para a apoteose do belo artístico e para sua dissolução; para a celebração da figura do garoto e para a desconstrução de sua inocência. Na presença radiosa e fulgurante do rapaz, um olhar que provoca dúvida e inquietação, um olhar que nada diz e tudo significa.

O projeto fotográfico de Rineke Dijkstra, intitulado Beach Portraits, parece revisitar essa problemática da infância-juventude observada em Thomas Mann e Luchino Visconti. De 1992 a 1998, viajando por uma série de localidades litorâneas situadas na América do Norte e na Europa Oriental, Dijkstra reuniu fotos tiradas de crianças e adolescentes em trajes de banho, tendo como pano de fundo o oceano e o espaço idílico da praia. Os retratos de Dijkstra dialogam de forma tensa com uma tradição de imagens da juventude, figurada exemplarmente por Mann e Visconti, introduzindo um olhar peculiar e atento sobre o corpo juvenil, com a captação de uma singularidade muitas vezes advinda da imperfeição, de uma quebra inesperada da pose. Nesse sentido, nos Beach Portraits, aspectos míticos da infância e da adolescência (e também da cultura) ganham uma nova luz a partir das contingências do enquadramento, da luz e do espaço, agenciando temporalidades e monumentalidades outras, para além dos lugares comuns do imaginário mítico.

A princípio, dir-se-ia que o romantismo das imagens da jovialidade é totalmente subvertido: as crianças e jovens olham diretamente para a câmera e são trazidos a uma distância quase íntima do espectador. Em detrimento da brilhante e enfumaçada panorâmica de Visconti, os pés sujos de areia é que ficam em evidência no espaço da foto, em contraposição ao mar muitas vezes reduzido à linha do horizonte, esmaecido e distante. O objetivo desse enquadramento do espaço é colocar o corpo da criança ou do jovem em destaque, reluzindo vigorosamente em contraponto ao fundo natural levemente escurecido ou desfocado. A natureza parece recuar e a câmera, colocada abaixo da linha de visão da pessoa fotografada, favorece uma visão atenta e detalhada do corpo inteiro, da vestimenta e das nuances da pose. Com esse recurso, o ideal de naturalidade aparentemente se desfaz, 
criando uma ambiência que certamente se contrapõe à poética de Thomas Mann, à aparição quase espectral de Tadzio, diluída nos matizes da paisagem e da amplidão.

A espontaneidade da juventude - tão valorizada pela cultura e imageticamente captada no pleno devir inconsciente - foi substituída pela pose, pela exposição consciente do retratado. As crianças de Dijkstra se dão à contemplação, e os jovens frequentemente procuram a lente do fotógrafo, cônscios e desejosos da atenção das câmeras, à procura quiçá do estrelato. O fotógrafo, por sua vez, agrega tecnicamente todos os recursos para a observação minuciosa, a partir de um olhar que lança luz e se aproxima - às vezes incomodamente - de seu objeto.

De fato, a técnica de Rineke Dijkstra busca a clareza total, a retratação que se acredita in natura do corpo juvenil, e não raro essa intencionalidade acaba por dotar os corpos de uma espécie de aura grandiosa. O corpo é observado de um ponto de vista inferior que lhe aumenta as dimensões, fazendo-o emergir em todos os detalhes. A sua centralidade surge na medida em que é focalizado e iluminado de forma a reluzir em detrimento do fundo oceânico, que recua para dar total primazia à superfície corporal (ver fig. 1). O resultado é um olhar hiper-realista sobre o corpo retratado, banhado de uma luz ao mesmo tempo realista e estranhamente sacralizadora, não apenas ressaltando as imperfeições ou traços peculiares de cada corpo, mas tornando-os plásticos, singulares, orgânicos:

Tudo é muito mais detalhado, sendo que o efeito é que a fotografia se torna mais realista que a própria realidade. $\mathrm{O}$ foco da imagem permite aproximar-se muito mais da pessoa, uma vez que o detalhe surge com uma nitidez translúcida (DIJKSTRA, 2012b, p. 46).

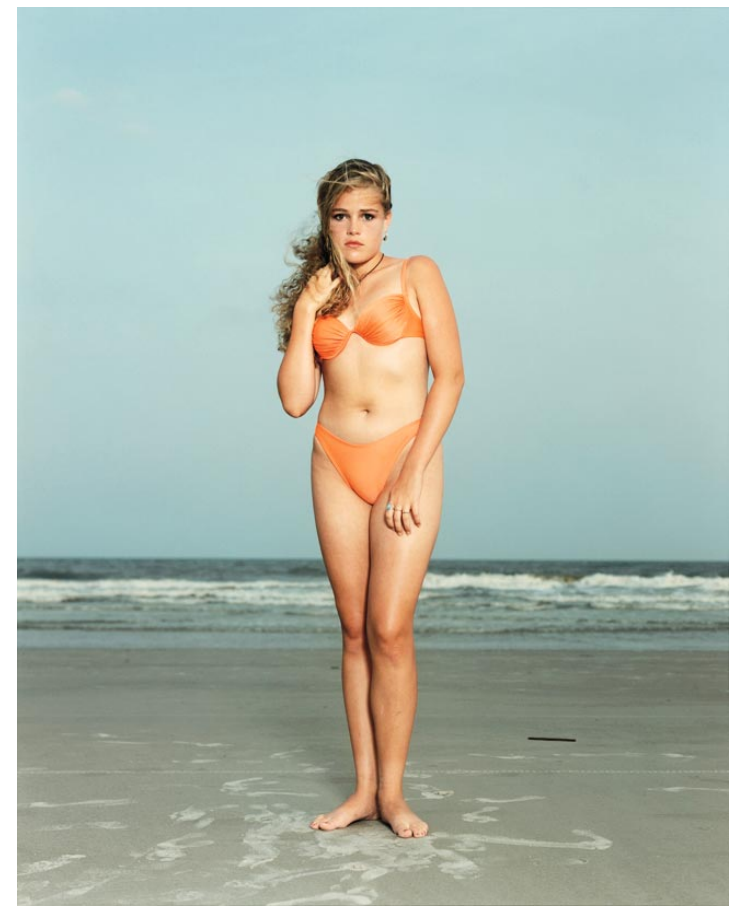

Figura 1 ("Hilton Head Island, S.C., USA, June 27, 1992") 
O corpo, assim, atabalhoadamente ou de forma espontânea, deixa transparecer a combinação de uma série de traços posturais: clichês da feminilidade e da masculinidade, posturas atléticas ou lânguidas, sedutoras ou simplesmente peculiares. Os adolescentes são flagrados reproduzindo gestos culturais reconhecíveis e clicherizados, a despeito da capacidade por vezes limitada do corpo de estar em dia com os ideais estéticos da cultura de massas. Por outro lado, as crianças surgem numa colagem inusitada de poses: formas roliças de garoto que se tornam subitamente femininas (cf. foto intitulada "Dubrovnik, Croatia, July 13, 1996"), contradições entre o extremamente anguloso e o encorpado ("Kolobrzeg, Poland, July 23, 1992"), um contrapposto indicando uma dubiedade de gênero ("Kolobrzeg, Poland, July 27, 1992") e, quase sempre, a face em total estranhamento diante da câmera. Enfim, crianças e adolescentes, inevitavelmente, surgindo como avatares de uma transição, exemplaridade do convívio entre extremos, de identidades em formação.

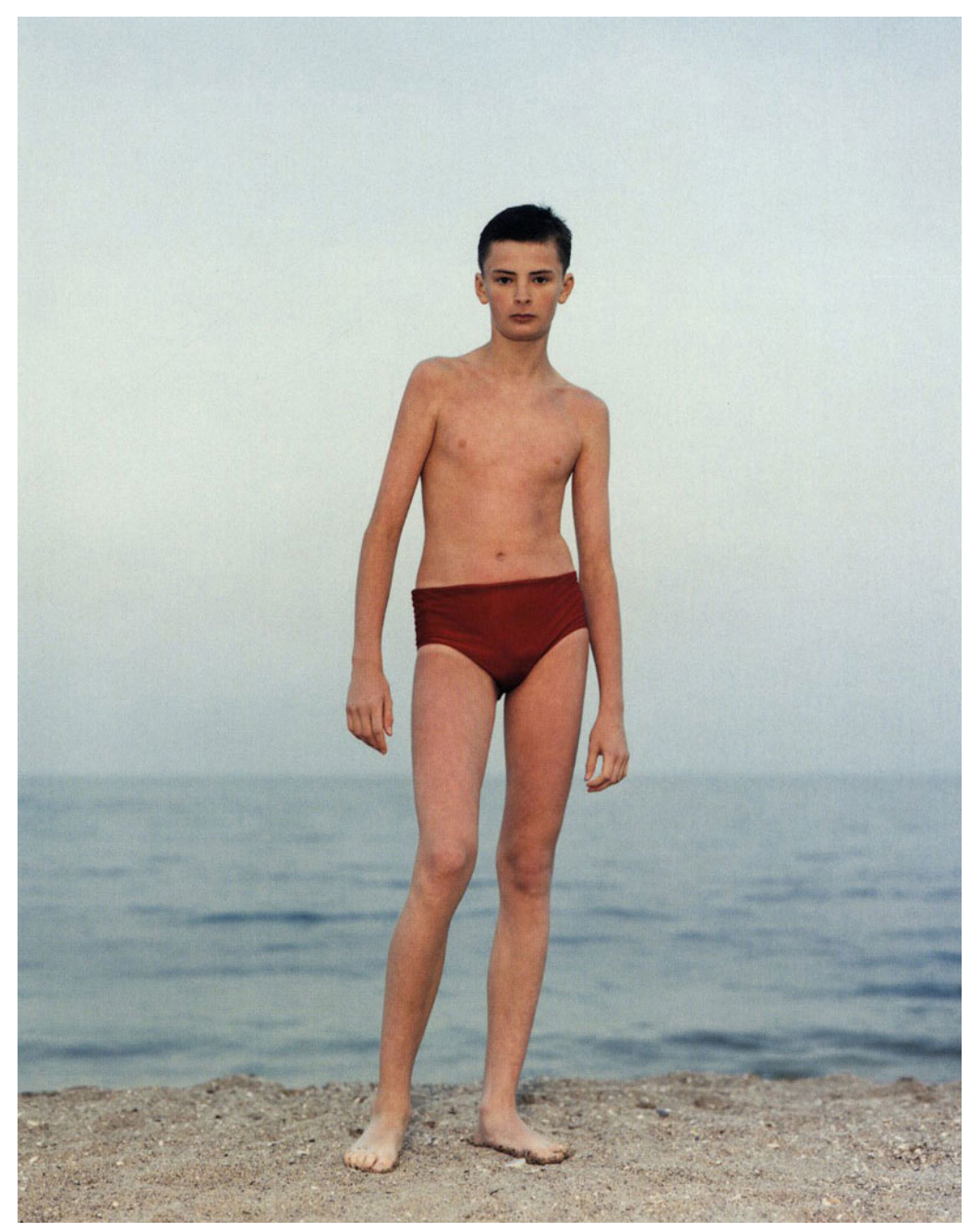


Por outro lado, é interessante notar que um difuso elemento mítico se imiscui nesse processo fotográfico. A monumentalidade surge inesperadamente dentre escolhas técnicas como a luz, o foco e o espaço, que acabam por concorrer no estabelecimento de uma exemplaridade e de uma circularidade temporal, típicas das imagens míticas. É inequívoca a presença sutil de uma tendência quase sempre modelar que as fotos assumem, como se fossem uma figuração exemplar de um estágio confuso e insondável da experiência humana. Totalmente desprovida de uma emanação mágica ou religiosa, a grandeza e a exemplaridade das crianças e dos jovens reencontram a esfera do mito na autoapresentação e na sustentação do corpo no retrato - seja de forma caricata e afetada (por exemplo, na encenação peculiar da masculinidade na fig. 2), seja reencenando inusitadamente a iconografia tradicional (cf. a muito comentada Vênus da fig. 3) -, plasmando artisticamente as ambiguidades das primeiras décadas de nossa vida.

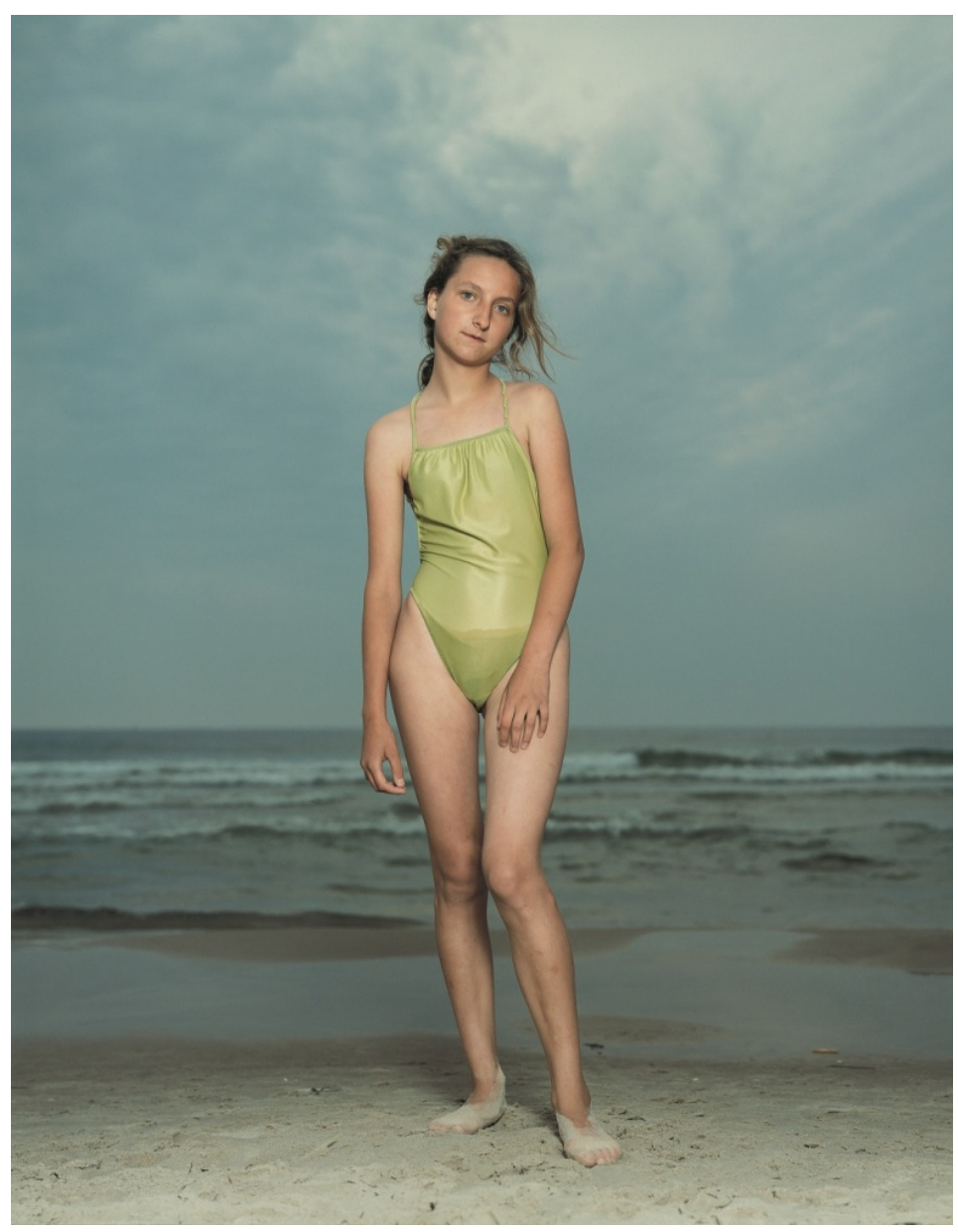

Figura 3 ("Kolobrzeg, Poland, July 26, 1992") 
De forma curiosa, a tentativa realista (e de certa forma idealista) de Dijkstra de capturar o jovem ou a criança na sua singularidade, a partir de um olhar fascinado pelos detalhes do corpo, frequentemente acaba conferindo à pose dos indivíduos retratados uma pretensa grandeza ritual, conscientes estão eles (principalmente os adolescentes) de serem fotografados, num momento em que a autoimagem se torna sua principal preocupação. As crianças e os jovens parecem estar posando para a "eternidade":

Existe uma seriedade e uma esperança nos Beach Portraits, uma gravidade muito próxima de uma cena batismal: eles possuem uma monumentalidade consciente, exercendo um contrapeso deliberado à tenuidade psicológica e à complexidade subjetiva (PHILLIPS, 2012, p. 19, tradução minha).

Por seu turno, reforçando ainda mais esse aspecto e introduzindo o que chamei acima de circularidade temporal, a paisagem praiana, mesmo recuada ao fundo em favor da monumentalidade do corpo juvenil, permanece como imantação simbólica do balneário, incorporando uma espécie de onirismo que surge precisamente da relativa obscuridade com que aparece na foto. $\mathrm{O}$ mar, especialmente em algumas imagens, resiste como miragem ou fundo irreal, e esse irrealismo apenas torna ainda mais peculiar a aparição da criança ou do jovem, iluminados pelo flash em contraposição a uma paisagem difusa, muitas vezes de contornos quase sobrenaturais (cf. a combinação insólita do tropical com o fundo tenebroso da fig. 4).

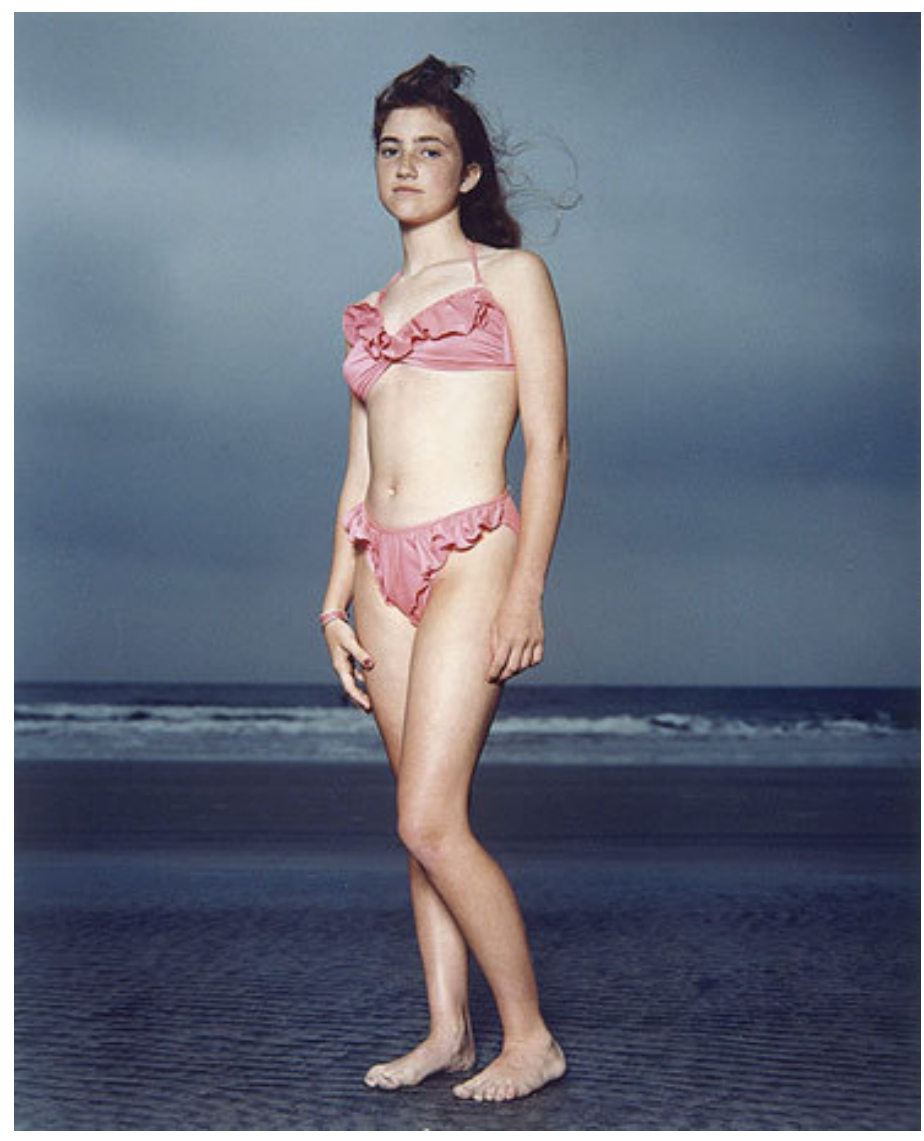


O espaço se configura, nesse sentido, como cercania que retira o corpo retratado da contingência histórica e que, ao mesmo tempo, demarca a singularidade desse mesmo corpo, reforçando um traço específico do retrato como gênero fotográfico. Segundo Thierry de Duve (1978), o retrato prima por ser uma exposição petrificada do tempo ("time exposure"), por meio da captação de um momento efêmero e seu consequente congelamento para apreciação e reencenação infinitas: "[O time exposure $]$ Lida com uma vida imaginária que é autônoma, descontínua e reversível, porque essa vida não se localiza em nenhum lugar a não ser na superfície da fotografia" (DUVE, 1978, p. 116, tradução minha). A articulação entre espaço e atemporalidade, portanto, confere ao trabalho de Rineke Dijkstra o aspecto cíclico das imagens míticas, e assim:

Permite ao espectador viajar através da imagem, escolhendo parar aqui e ali, e, fazendo isso, ampliar a monumentalidade de um detalhe ou ainda considerá-lo como porta de entrada. O tipo de temporalidade implicado nessa recepção é a alternância de expansão e contração, sístole e diástole (DUVE, 1978, p. 123, tradução minha).

Pode-se dizer, nesse sentido, que os retratos de Rineke Dijkstra pulsam como figurações universais da infância e da adolescência, utilizando-se precisamente dos elementos contingentes do corpo, do espaço e do realismo fotográfico. Manipulados de forma a monumentalizar os objetos em questão, esses elementos contingentes formarão um todo apartado do tempo histórico, aberto à contemplação afetiva, atenta e, consequentemente, estética dos jovens e das crianças. É como se o corpo em questão, conforme diria Roland Barthes quando fala do mito, tivesse "sido criado nesse instante, para mim, como um objeto mágico surgindo no meu presente, sem nenhum rasto da história que o produziu" (BARTHES, 2003, p. 217, grifo do autor). Na perspectiva da formação de um mito não-sagrado, nascido no seio da técnica fotográfica, testemunhamos algo que "é simultaneamente imperfectível e indiscutível; o tempo e o saber nada lhe podem acrescentar ou subtrair" (idem, p. 222).

É assim que os Beach Portraits partilham de um certo apelo mitopoético que também perpassaria as obras de Thomas Mann e de Luchino Visconti. Por meio de estratégias representativas completamente distintas, permanece a tentativa de captar a beleza singular da infância e da juventude, explorando a potência estética de um universo alheio à estratificação e à sistematização do mundo adulto, com todas as imperfeições e nuances singulares. Dijkstra divide com Mann e Visconti a busca por uma essência mesmo que efêmera —, por uma autenticidade, que demarque a infância e a adolescência como momentos privilegiados da vida humana. Uma busca talvez ingênua, com inequívoco apelo romântico, mas no sentido de que busca desconstruir certos clichês acerca da inocência e da pureza, procurando a beleza por trás desses corpos inseguros, tão corajosamente imperfeitos. Afirma, de fato, Dijkstra: 
Para mim, o que mais importa é uma certa essência da experiência, não a vida pessoal. Apesar de meus retratos serem na sua maioria individuais, eu gostaria que eles se tornassem mais universais, como metáforas que representem todo um grupo (DIJKSTRAb, 2012, p. $50)$.

É importante ressaltar, entretanto, que as crianças e jovens fotografados pela artista holandesa não se constituem como "metáforas universais" a partir de um conjunto harmonioso e estetizado de arte, corpo e espaço, como pareceria ser o caso de Morte em Veneza. Aqui, talvez, resida o divisor de águas, a diferenciação cabal entre aquilo que buscam Mann e Visconti, e aquilo que Dijkstra acaba por capturar nos seus retratos: a diferença, enfim, entre o que seria um mito clássico e um mito contemporâneo.

A praia de Morte em Veneza dilui as fronteiras entre mar, areia e corpo, embalados, no filme de Visconti, pela magistral trilha sonora de Gustav Mahler. A aparição fulgurante de Tadzio não só ofusca os sentidos do observador, como também recobre o corpo apolíneo do jovem com um véu em que se matizam e se sublimam erotismo, sensorialidade, desejo e arte. Na contramão desse processo, o olhar realista de Dijkstra busca a contingência e a imperfeição de uma fase da vida marcada pela incompletude. Seu trabalho procura, na contramão do enlevo, despertar a percepção do espectador para os detalhes singulares de uma corporeidade, fazendo reluzir esteticamente — como uma imagem mítica simulada um corpo estranho e inseguro.

Assim, se, no plano da fatura, tanto Mann, Visconti e Dijkstra buscam engrandecer suas criações, dar-lhes relevância e proeminência artística, é certo que eles se diferenciam nas direções para as quais seus trabalhos apontam. Tadzio, ao fim do livro e do filme, aponta para o horizonte, indicando-nos o reino da pura beleza e da transcendência. Nesse sentido, representa o epítome do imaginário idealista que cerca a infância e a juventude, que descortina precisamente o éden do qual todos nós, adultos, fomos expulsos. Em contrapartida, para onde apontam as crianças e os jovens gloriosamente estranhos de Rineke Dijkstra? O que mostram os membros levemente tortos, os olhares perdidos e as poses "quase" perfeitas? A imagem monumental da imperfeição, ao contrário do classicismo estético, retrata antes uma vacuidade, algo que escapa ao conjunto do retrato, mas que no entanto ali está.

A fotografia de Rineke Dijkstra parece privilegiar aquilo que escapa ao retrato, à praia e à pose, e suas metáforas universais parecem ser finamente construídas para sugerir exatamente esse vazio. Através da luz, da praia e da translucidez da foto, a captação de uma contingência corporal singular e exemplar, que nos comove pela sua universalidade. Porém, uma universalidade balbuciada através de pés levemente tortos, de pernas mal equilibradas, de torsos desajeitadamente sustentados, de mãos que não se sabe onde por.

Corpos incontroláveis que falham no exato momento da tensão e do controle: para Rineke Dijkstra, talvez seja isso o que torna a infância e a juventude idades tão inequivocamente míticas, belas e universais. As crianças e os jovens olham diretamente 
para nós e se tornam emblemáticos precisamente pelo desconforto e pela autoconsciência, pela tentativa malfada de controle. Afetos que valem não tanto por si, mas por sua renitente inutilidade. Inúteis, por mais que se tente sustentar a pose, manter a imagem, controlar o corpo.

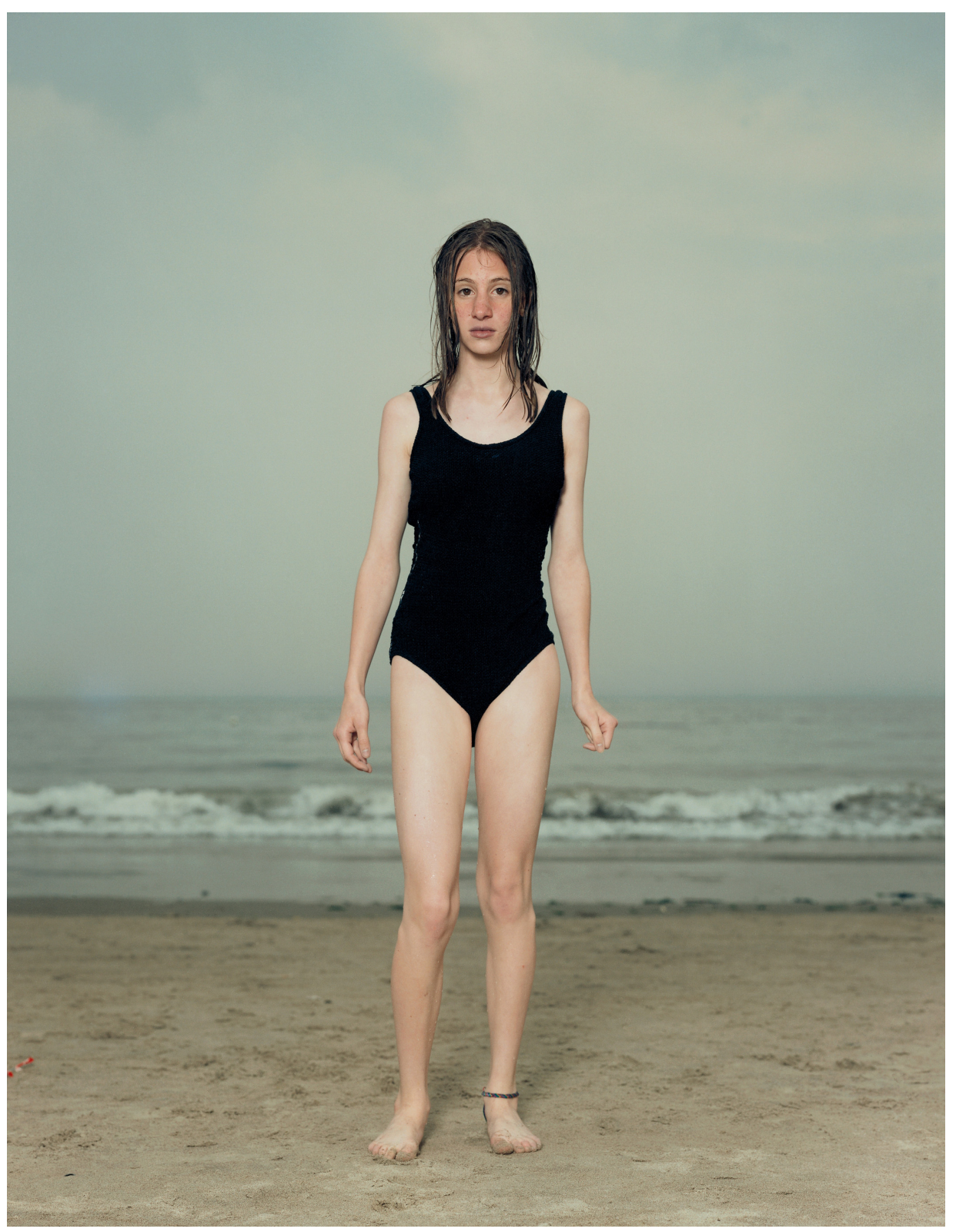

Figura 5 (“Coney Island, N.Y., USA, June 20, 1993”)

\section{Referências bibliográficas}

ARIÉS, Phillipe. Centuries of childhood. A social history of family life. Trad. Robert Baldick. New York: Vintage books, 1962. 
BARTHES, Roland. Mitologias. Trad. Rita Buongermino, Pedro de Souza e Rejane Janowitzer. Rio de Janeiro: Difel, 2003.

DIJKSTRA, Rineke. "Beach Portraits". In: Rineke Dijkstra: a retrospective. New York: Guggenheim Museum, 2012a, pp. 62-95.

. "Realism in the smallest details". Entrevista concedida a Jan van Adrichem. In: Rineke Dijkstra: a retrospective. New York: Guggenheim Museum, 2012b, pp. 45-

60.

Rineke Dijkstra: a retrospective. New York: Guggenheim Museum, 2012c.

DUVE, Thierry de. "Time exposure and snapshot: the photograph as paradox". In: October, v. 5, 1978. Acessado em http://www.jstor.org/stable/778649, 3 de dezembro de 2013.

HIGONET, Anne. Pictures of innocence. The History and crisis of ideal childhood. New York: Thames and Hudson, 1998.

KUHN, Reinhard. Corruption in paradise. The child in western literature. Hanover: Brown University Press, 1982.

LUMBY, Catharine. "Ambiguity, children, representation, and sexuality". In: BARTOLONI, Paolo; STEPHENS, Anthony (orgs.). CLCWeb: Comparative Literature and Culture. Vol. 12, n. 4, dec. 2010. Acessado em http://docs.lib.purdue.edu/cgi/viewcontent.cgi?article=1673\&context=clcweb, 2 de outubro de 2013.

MANN, Thomas. Tonio Kroger / A morte em Veneza. Trad. Maria Deling. São Paulo: Abril Cultural, 1979.

PHILLIPS, Sandra S. "Twenty years of looking at people". In: DIJKSTRA, Rineke. Rineke Dijkstra: a retrospective. New York: Guggenheim Museum, 2012, pp. 13-27.

ROUSSEAU, Jean-Jacques. Emílio ou Da Educação. Trad. Sérgio Milliet. Rio de Janeiro: Bertrand Brasil, 1995.

VISCONTI, Luchino. Morte em Veneza [Filme]. Produção e direção de Luchino Visconti. Itália, Alfa cinematografia, 1971. 
${ }^{1}$ Fotograma disponível em: http://amc-nuncamais.blogspot.com.br/2006/07/o-negrume-do-ocaso-e-jubilosaesperana.html. Acessado em 29 de setembro de 2013.

${ }^{2}$ Todas as imagens de Rineke Dijkstra foram retiradas do catálogo da exposição "Rineke Dijkstra: a retrospective", ocorrida em 2012. Sobre o catálogo, conferir as referências bibliográficas. 